ISSN: 1641-4713; e-ISSN: 2081-1160

DOI: https://doi.org/10.36551/2081-1160.2021.28.111-140

\title{
Usos dos testemunhos como estratégia de denúncia da violência estatal durante a última ditadura civil-militar argentina (1976-1983)
}

\author{
Uses of testimonies as a strategy to denounce state violence during the last \\ Argentine civil-military dictatorship (1976-1983)
}

Marcos Tolentino

Universidade Estadual de Campinas (Unicamp), Brasil

ORCID iD: https://orcid.org/0000-0002-0977-397X

E-mail: marcosoat@hotmail.com

Recepción: 31.05.2021

Aprobación: 28.12.2021

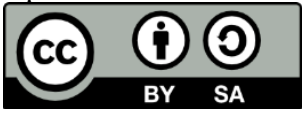

Resumo: O objetivo deste artigo é historicizar os usos dos testemunhos como estratégia de denúncia da violência estatal na Argentina, principalmente durante a última ditadura civil-militar (1976-1983). Nos interessa reconstruir suas lógicas de produção e circulação no país, partindo de questões como: quem testemunhava; quais organismos de direitos humanos recebiam seus relatos; como eles circularam; e como eles eram usados na produção de documentos diversos. Buscamos, assim, compreender os usos que os atores locais fizeram das linguagens e práticas então disponíveis na cultura dos direitos humanos internacional, adaptando-as à realidade concreta do país durante a última ditadura e à urgência de produzir suas próprias estratégias frente à adoção dos desaparecimentos como principal modalidade repressiva.

Palavras-chave: Argentina, direitos humanos, testemunho, denúncia, desaparecimentos

Abstract: The aim of this article is to historicize the uses of testimonies as a strategy of denounce
state violence in Argentina, particularly during the last civil-military dictatorship (1976-1983). We
are interested in reconstructing their logics of production and circulation in Argentina, starting from
questions such as: who testified; which human rights organisms received and produced testimonies;
how they circulated; and how they were used for the production of various documents. We thus
seek to understand the uses that local actors have made of the languages and practices that were 
available in the international culture of human rights, adapting them to the concrete reality of the country during the last dictatorship and the urgency to produce their own strategies in the face of the adoption of disappearances as the main repressive modality.

Keywords: Argentina, human rights, testimony, denounces, disappearances

\begin{abstract}
A mi hijo lo secuestran el 5 de mayo de 1977. Bueno, hago los llamados que creo y cuando voy a hacer la denuncia a la Asamblea [APDH] (...). Me dicen a mí que tengo que hacer un testimonio y digo: 'Pero iqué es?'. 'Usted ponga todos los datos de su hijo y todos los datos suyos, y lo que sepa o le contaron que pasó', me dicen (Adelina Alaye, citada em Madres de Plaza de Mayo Línea Fundadora, 2014, p. 46).
\end{abstract}

Ao analisarmos as discussões sobre memórias e representações do passado recente na América Latina, o testemunho ocupa um lugar central. Nas últimas décadas, essa categoria tem sido utilizada para referir-se a uma gama de narrativas distintas entre si, em diversos formatos e suportes, alcançando a produção cultural, os debates intelectuais e acadêmicos e algumas práticas que configuram as mobilizações em torno da defesa dos direitos humanos e as diferentes políticas estatais de memória.

Para alguns, o estatuto do testemunho na região se relaciona a um marco cultural amplo: a emergência da chamada "era das testemunhas", iniciada com a difusão de relatos de sobreviventes do Holocausto, a partir da década de 1960, na Europa e nos Estados Unidos, que resultou na valorização da testemunha como portadora da verdade e no reconhecimento ético do valor do seu relato para a reconstrução e a reparação de experiências passadas de violência (Franco \& Levin, 2007; Sarlo, 2007; Wieviorka, 1998). Para outros, o uso difundido dos testemunhos se relaciona às suas possibilidades de aproximar-se de outras formas do processo de construção de identidades nacionais, visibilizando desigualdades, relações de poder e experiências ignoradas pelas narrativas oficiais (Blanes \& Sáez, 2015). Há ainda uma concordância de que o estatuto do testemunho se baseia na atualidade do passado narrado no presente em que ele é produzido (Bacci \& Oberti, 2014).

A legitimidade alcançada pelos testemunhos na América Latina foi fruto de processos sociais, culturais e políticos. Na década de 1960, em um contexto de emergência de novos imaginários revolucionários, tais narrativas foram reconhecidas como aparatos culturais eficazes pela Revolução Cubana para a difusão dos ideais revolucionários. Alguns círculos literários incorporaram então entre 
suas categorias de produção o gênero do testemunho, reconhecendo o valor de obras que documentavam aspectos da realidade latino-americana (Basile \& Chiani, 2020; García, 2016). Com a instauração de ditaduras civis-militares e de regimes autoritários, entre as décadas de 1960 e 1980, o testemunho se afirmou como uma prática de resistência à violência estatal (Bonano, 2005). Nota-se então, a paulatina substituição da matriz revolucionária e de seus relatos de emancipação por outros que utilizavam a linguagem das narrativas humanitárias. Enquanto os primeiros testemunhos denunciaram as violações em termos históricopolíticos, entendidas como exercícios de poder que almejavam manter a ordem socioeconômica vigente; a partir do início da década de 1970, esta denúncia se articulou em torno da noção de violação aos direitos humanos, demanda de tipo ética e jurídica, antes que política (Basile \& Chiani, 2020).

Essa reconfiguração se relacionou à articulação na América Latina e no exterior de redes transnacionais de direitos humanos, nas quais organizações locais se conectaram entre si e com atores internacionais, dedicando-se à denúncia humanitária, o que envolvia a divulgação de informações sobre os crimes de tortura, desaparecimento forçado de pessoas, prisões ilegais e assassinatos (Sikkink, 2006). A atuação em rede resultou ainda em uma crescente homogeneidade nas formas de se tomar os testemunhos e, consequentemente, em seus conteúdos, priorizando a descrição fática das práticas que violavam a integridade física ou psíquica das vítimas. Nesse processo, a circulação dos testemunhos relacionou-se à tarefa de difusão dos saberes acumulados pelos organismos de direito humanos sobre as violações aos direitos humanos e suas vítimas (Crenzel, 2021; Markarian, 2006; Scocco, 2020). Com o fim destes regimes, e em distintos momentos em cada país, estes saberes foram ratificados pelas políticas de memória implementadas que, além de produzir novos testemunhos, utilizaram aqueles produzidos nas décadas anteriormente nas investigações realizadas por comissões de verdade e como provas nas causas judiciais abertas contra os responsáveis materiais pela violência estatal.

O estatuto do testemunho na América Latina relacionou-se, assim, ao seu uso como estratégia de denúncia da violência estatal durante as recentes ditaduras civis-militares e regimes autoritários da região. No caso da Argentina, sua produção e circulação foram eixos importantes do acionar dos organismos locais de direitos humanos para denunciar publicamente as práticas que configuravam as modalidades repressivas implementadas pela última ditadura (1976-1983) e conseguir solidariedade no plano internacional contra a mesma, afirmando-se como uma prática própria do campo dos direitos humanos (Jelin, 2017). 
A associação entre testemunho e direitos humanos deve ser entendida a partir de uma perspectiva que considere a interação das modalidades da violência institucionalizada pelo Estado e as modificações das respostas sociais frente a elas (Solis, 2014). A história argentina no século XX, foi marcada por sucessivos golpes de Estados, ditaduras e governos democráticos com traços autoritários que implementaram uma sistemática perseguição a certos grupos e identidades políticas, que por sua vez, gerou a articulação de atores individuais e coletivos que, por meio de distintas práticas, atuaram publicamente em defesa das vítimas, entre as quais esteve o uso de testemunhos. Com o golpe de Estado de 24 de março de 1976, este uso se acentuou frente às práticas clandestinas e anônimas que configuraram o desaparecimento forçado de pessoas, adotado pela última ditadura argentina como a sua principal modalidade repressiva; e ao discurso ditatorial que inicialmente negou e depois justificou a existência de desaparecidos, apontando-os como resultados inevitáveis da "guerra anti-subversiva". Devido à política de negação e de silêncio exercida pelo Estado e por alguns setores da sociedade política e civil, o testemunho se afirmou como uma das principais estratégias de interpelação pública e de afirmação de outra verdade.

Entretanto, como aponta o depoimento da madre de Plaza de Mayo Adelina Alaye com o qual abrimos este artigo, este processo pressupôs um aprendizado por parte dos denunciantes do que era um testemunho e como produzi-los. Em 05 de maio de 1977, seu filho, Carlos Esteban, miliante da Juventud Universitaria Peronista (JUP), foi sequestrado em Ensenada, Província de Buenos Aires. A partir de então, Adelina aproximou-se dos organismos de direitos humanos em Buenos Aires, tornando-se uma das fundadoras de Madres de Plaza de Mayo. O trecho que citamos demonstra que este processo de se tornar uma mãe de desaparecido e uma militante de direitos humanos pressupôs um aprendizado da gramática e das práticas próprias do campo dos direitos humanos, o que abre a possibilidade para analisarmos os processos de sua difusão e apropriação entre os sujeitos que participaram da produção de denúncias.

Pensando nisso, o objetivo deste artigo é historicizar o uso dos testemunhos como estratégia de denúncia da violência estatal na Argentina, principalmente durante a última ditadura civil-militar. Mais do que analisar os testemunhos em si, nos interessa reconstruir suas lógicas de produção e circulação na Argentina, partindo de questões como: quem testemunhava; quais organismos de direitos humanos recebiam seus relatos; como eles circularam; e como eles eram usados na produção de documentos diversos. 
Nossa análise se centrará nas possibilidades de testemunhar e de tornar públicas as informações dos testemunhos dentro da Argentina. A bibliografia sobre os processos de denúncia humanitária durante a última ditadura geralmente analisa as lógicas de produção e de circulação de testemunhos por meio das estratégias desenvolvidas por organizações de exilados e por organismos não governamentais de atuação regional e internacional nas redes transnacionais de direitos humanos. ${ }^{1}$ Em relação aos organismos locais de direitos humanos, afirmase que eles centraram suas denúncias no exterior, devido a um contexto político interno que apresentava oportunidades políticas restritas. Entretanto, algumas iniciativas também foram desenvolvidas localmente, em diálogo com as possibilidades de denúncia fora do país, e que merecem a nossa atenção para compreendermos os usos que os atores locais fizeram das linguagens e práticas então disponíveis no campo dos direitos humanos, adaptando-as à realidade concreta da Argentina durante a última ditadura e à urgência de produzir suas próprias estratégias frente aos casos de desaparecimentos.

\section{ANTECEDENTES DOS USOS DO TESTEMUNHO COMO ESTRATÉGIA DE DENÚNCIA}

$\mathrm{Na}$ Argentina, a produção literária de Rodolfo Walsh é apontada como um precedente para o uso dos testemunhos como modo de intervenção política e para o início de uma cultura da denúncia testemunhal baseada na descrição detalhada da aplicação de tormentos (García, 2016; D’Antonio, 2017). Seu livro Operação Massacre, publicado em 1957, foi o resultado de uma investigação sobre um procedimento repressivo que a Revolução Libertadora executou contra um levante cívico-militar a favor do presidente deposto, Juan Dominguez Perón, em junho de 1956. Ao longo de um ano e meio, Walsh entrevistou sete sobreviventes deste episódio.

A partir da ditadura autodenominada Revolução Argentina (1966-1973), a produção de testemunhos com fins de denúncia não se restringiu à literatura, tornando-se uma resposta ao aumento qualitativo da perseguição e do encarceramento massivo de militantes de esquerda, ativistas sindicais e militantes estudantis, e ao uso generalizado da tortura (Eidelman, 2018). Tais relatos se tornaram fontes para a produção de publicações por organizações de defesa e de solidariedade aos presos políticos. Entretanto, a solidariedade com os presos políticos não

\footnotetext{
${ }^{1}$ Para uma discussão sobre a circulação de denúncias no exterior, ver: Basualdo, 2019; Catoggio, 2016, 2018; Crenzel, 2021; Franco, 2008; González Tizón, 2021; Jensen, 2010.
} 
foi uma prática anterior que se iniciou nesse período. A Liga Argentina por el Derecho del Hombre (LADH), por exemplo, surgiu em 1937, no marco do golpe de 1930 e da repressão aos grupos identificados como comunistas. Apesar de sua origem estar vinculada ao Partido Comunista Argentino (PCA), a LADH afirmou-se como um espaço plural e de defesa e solidariedade a presos políticos de todas as vertentes. Entre as décadas de 1940 e 1970, a LADH criou filiais em todo o país, ampliou e aprofundou o seu trabalho jurídico, de solidariedade aos presos políticos e a seus familiares e de investigação e denúncia das violações às liberdades constitucionais (Reboursin, 2008; Vecchioli, 2012).

No contexto da Revolução Argentina, multiplicaram-se os espaços dedicados à questão dos presos políticos, nos quais participaram alguns advogados comprometidos com sua a defesa legal, companheiros de militância dos presos e seus familiares. Suas ações contribuíram para conformar a categoria de "preso político", distinguindo-o simbolicamente de um preso comum para obter alguns tratamentos especiais nas condições de detenção e adequar as estratégias jurídicas de defesa às razões que resultaram em seu encarceramento. Nesse contexto, a LADH passou a utilizar a consigna da "vigência dos direitos humanos", associando-a às condições dos presos políticos e à luta pela sua liberdade (Reboursin, 2008).

Além da problemática dos presos políticos, organizações como o Foro de Buenos Aires por la Vigencia de los Derechos Humanos e a Comisión de Familiares de Presos Políticos, Estudiantiles y Gremiales (CoFaPPEG) dedicaram-se também à denúncia da atividade repressiva clandestina de grupos parapoliciais e paraestatais vinculados com setores nacionalistas e católicos e das primeiras experiências de sequestros e desaparecimentos realizados por serviços de inteligência pertencentes à Polícia Federal Argentina (PFA) e ao Exército. Estas atividades repressivas novas foram uma resposta à etapa aberta pelo Cordobazo, ocorrido em maio de 1969, que resultou no questionamento amplo do projeto político da ditadura, no incremento das ações armadas das organizações político-militares - sobretudo das ações protagonizadas por Montoneros e pelo Partido Revolucionario de los Trabajadores - Ejército Revolucionario del Pueblo (PRT-ERP) e na radicalização de diferentes setores sociais (Eidelman, 2018).

Ações de apoio, solidariedade e defesa dos presos políticos se intensificaram entre 1971 e 1973, assim como as denúncias que, por meio da documentação e difusão de casos de tortura e das condições carcerárias, e da apresentação de listas sobre sequestros, assassinatos e detenções; buscavam gerar um impacto na opinião pública para reforçar uma consciência anti-represiva e anti-ditatorial (Scocco, 2020). Além disso, foram publicados informes com testemunhos de 
presos políticos, de familiares de vítimas de sequestros e desaparecimentos e de algumas pessoas que haviam sobrevivido a esta prática. Os repertórios discursivos desses documentos não se articulavam em torno dos direitos humanos: compartilhavam entre si uma retórica da militância revolucionária, colocando-se como denúncias da "repressão sofrida pelo povo argentino", cuja solução era a "revolução social" e a "liberação nacional" (Alonso, 2011; Chama, 2016; Crenzel, 2021; Scocco, 2018).

Após o chamado Massacre de Trelew, os testemunhos de três sobreviventes foram centrais nas disputas em torno do significado deste evento. Em 22 de agosto de 1972, na base Almirante Zar, localizada a alguns quilômetros da cidade de Trelew, na região da Patagônia, dezenove presos políticos, que uma semana antes haviam participado de uma tentativa de fuga da prisão de Rawson, foram metralhados no corredor que separava as suas celas, pelos oficiais responsáveis por sua custódia. Alguns foram depois alvejados com tiros de armas de curta distância, para não deixar testemunhas vivas. Entretanto, três conseguiram sobreviver e contar o que havia ocorrido: María Antonia Berger, Ricardo René Haidar e Alberto Camps. Produziram-se, então, duas versões sobre os fatos: versão oficial da ditadura, segundo a qual os dezesseis presos políticos haviam sido abatidos durante uma tentativa de fuga, omitindo, assim, o caráter criminoso da execução; e a versão das publicações da esquerda, que denunciaram que havia ocorrido um massacre, utilizando os testemunhos dos sobreviventes para expor outra verdade, além das tentativas da ditadura de silenciá-los. A partir do primeiro aniversário do episódio, os testemunhos dos sobreviventes tornaram-se ainda ferramentas para a rememoração do Massacre de Trelew e do compromisso militante de suas vítimas; e foram a principal fonte para a publicação do livro reportagem La Patria Fusilada, de Paco Urondo (Bonano, 2005; Pittaluga, 2006).

No breve período democrático entre as duas ditaduras (1973-1976), encontramos poucas menções na bibliografia disponível sobre o uso de testemunhos como parte do repertório de ação de grupos que denunciaram o avanço repressivo neste período. Nos estudos sobre a repressão na Argentina, o ano de 1974, é apontado como um momento de incremento do conflito social, resultado do crescente uso da violência política por organizações político-militares, pelos grupos paraestatais e pela repressão estatal. Esta última se reestabeleceu através da sanção de leis repressivas, resultando novamente no aumento das prisões por causas políticas e na aprovação de decretos que criaram uma situação de excepcionalidade jurídica para a perseguição a todas as manifestações tidas como "subversivas". A partir de 1975, as Forças Armadas foram incorporadas nas "tarefas 
antissubversivas", com o inicío do "Operativo Independencia", comandado pelo Exército para destruir uma guerrilha rural PRT-ERP na província de Tucumán. A participação dos militares na repressão à "subversão" se ampliou através de novos decretos que colocaram sobre o seu controle operacional as forças policiais e penitenciárias de todas as províncias, que estenderam à âmbito nacional as operações militares e de segurança até então desenvolvidas apenas em Tucumán, e que organizaram tais operações ao dividir o território nacional em zonas nas quais a repressão operaria militarmente sob um único mando. A normatização de uma repressão estatal tida como legal não resultou no fim do acionar dos grupos paraestatais, que continuaram com suas ameaças de morte, sequestros e assassinatos, contribuindo para gerar um clima de crescente violência. Logo, os estudos recentes sobre a repressão na Argentina apontam que, entre 1974 e 1976, configurou-se um estado de exceção, baseado na lógica de aniquilamento de um inimigo interno difuso; em paralelo a um reconhecimento das Forças Armadas por setores sociais e políticos como responsáveis "legítimos" para reestabelecer a "ordem" (Franco, 2012; Àguila, 2016; Pontoriero, 2016; Scocco, 2018).

Ainda são pouco estudadas as maneiras que as organizações de defesa e de solidariedade dos presos políticos e os organismos de direitos humanos reagiram à essa escalada repressiva, assim como o lugar do testemunho no seu repertório de ação. Com o fim da ditadura e a anistia aos presos políticos, em 1973, algumas organizações de solidariedade atravessaram um momento de desarticulação, mas, com o avanço da repressão, algumas delas voltaram a atuar publicamente e surgiram organizações novas. Diferentemente das experiências anteriores, as novas organizações eram formadas por familiares de presos, sem vínculos com partidos políticos ou organizações político-militares. Em 1975, e nos primeiros meses de 1976, surgiram também organismos formados por pessoas com diversos perfis que reivindicavam os direitos humanos como paradigma da sua ação frente à intensificação das formas de violência, como a Asamblea Permanente por los Derechos Humanos (APDH) e o Movimiento Ecuménico por los Derechos Humanos (MEDH) (Jelin, 2017).

As condições desses novos organismos de denunciar publicamente os episódios repressivos se modificaram frente à uma violência estatal que cada vez mais se deslocava do legal para o clandestino; da inclusão de alguns denunciantes, principalmente os advogados, entre os alvos dos grupos paraestatais; e das progressivas restrições impostas à imprensa. Esse processo limitou práticas como as conferências de imprensa e a publicação de informes com testemunhos, em detrimento da solidariedade e o apoio jurídico a familiares e presos políticos, 
o envio de cartas pressionando autoridades e a publicação de matérias pagas em jornais (Alonso, 2011; Solis, 2014; Scocco, 2018). Além disso, o uso generalizado da violência pode ter gerado uma dificuldade entre os denunciantes de produzir sentidos sobre o que estava passando, o que prejudicava a produção de testemunhos (Scocco, 2018). Porém, nas sedes dos organismos paulatinamente, os testemunhos dos familiares das pessoas desaparecidas tornaram-se fonte de informação para a produção de um tipo de documento que se tornaria uma das principais estratégias legalistas às detenções ilegais e, consequentemente, um dos principais registros dos desaparecimentos: os habeas corpus, enviados para a Justiça demandado respostas oficiais sobre o paradeiro daqueles que "eram levados" (Da Silva Catela, 2001).

Os primeiros modelos de habeas corpus circularam em um folheto produzido pelo Servicio Paz y Justicia (SERPAJ) em 1975, em uma campanha de difusão local da Declaração Universal dos Direitos Humanos (Bruschtein, 2002). Posteriormente, os formulários de denúncia utilizados pela APDH para a produção de habeas corpus se basearam em outros elaborados para reunir denúncias pela Comissão Interamericana de Direitos Humanos (CIDH) e pela Anistia Internacional (AI), que se tornaram modelos de denúncia após o golpe de Estado no Chile, em 1973. Priorizava-se nestes formulários, como em uma apresentação judicial, o registro de dados de identificação das vítimas (nome, idade, data de nascimento, gênero, nacionalidade, ocupação ou profissão), uma descrição detalhada das circunstâncias do sequestro, a identificação de outras testemunhas dos fatos e de dados que permitissem identificar os responsáveis por eles, e as outras gestões realizadas pelo responsável pela denúncia e as respostas obtidas (Crenzel, 2015).

Em um registro distinto, que não corresponde ao universo das organizações de direitos humanos, a veiculação de testemunhos de militantes desempenhou um papel importante em publicações de organizações político-militares revolucionárias que então atuavam clandestinamente, como Estrella Roja (PRTERP) e Evita Montonera (Montoneros). Eles eram veiculados para informar sobre o acionar das organizações; para homenagear os mortos em ação e exaltar suas qualidades como "bons combatentes; e para contribuir para a formação das subjetividades militantes, baseadas num conjunto de normas de condutas (Oberti, 2015; Slipak, 2015). 


\section{A RECEPÇÃO DE TESTEMUNHOS DOS FAMILIARES DE DESAPARECIDOS}

Durante a última ditadura civil-militar (1976-1983), o testemunho se tornou a principal forma para se denunciar as modalidades repressivas então implementadas. Para entendermos como se deu esse processo, precisamos primeiro compreender de que maneira se configurou a repressão neste contexto. Os estudos sobre a repressão apontam que a última ditadura foi uma experiência inédita na história da violência política na Argentina, devido ao uso sistematizado de métodos clandestinos. Por outro lado, apontam que essa novidade deve ser pensada também como parte de um processo repressivo a médio prazo, com continuidades e descontinuidades, que criaram as condições necessárias para efetividade de um plano sistemático, ilegal e de alcance nacional de desaparecimento forçado de pessoas. A execução deste plano partiu de normas e de regulamentos militares vigentes, assim como um conjunto normativo sancionado pelo Estado Nacional, entre 1974 e 1976, que, ao ser referendados ou ampliados pela ditadura, outorgaram um marco jurídico-legal para o exercício da repressão (Águila, 2013; Franco, 2015; Portoriero, 2017).

Esse conjunto de práticas regulamentadas se articularam com um acionar clandestino executado pelos grupos de tarefa, formados por quadros militares, das forças policiais e dos grupos paraestatais, que já agiam de forma dispersa, e que passaram a ser coordenados pelas Forças Armadas. Os grupos de tarefa adotaram como modalidade repressiva principal o desaparecimento, uma prática que já era utilizada anteriormente, mas sem a mesma generalização e sistematicidade com que foi aplicada durante a última ditadura. A partir do golpe de 24 de março de 1976, o desaparecimento passou a girar em torno de uma série de situações iniciadas com a seleção, por serviços de inteligência policiais e militares, de alvos específicos. Entre esses alvos estavam os militantes das organizações políticomilitares e de suas frentes legais ou estruturas de superfície (vicinais, sindicais e estudantis); os militantes de outras correntes da esquerda; e, com o avanço das tarefas de denúncias, familiares, religiosos e advogados envolvidos nas buscas pelos desaparecidos. Ao serem sequestradas, algumas dessas pessoas tinham os seus bens saqueados e eram levadas para um centro clandestino de detenção, onde eram torturadas para a obtenção de informação e a produção de novos sequestros. Após um tempo indeterminado, a grande maioria foi assassinada. Os seus corpos apareceram publicamente em enfrentamentos forjados ou foram ocultados. Os que sobreviviam às torturas poderiam ser levados para outros centros clandestinos; permaneciam desaparecidas por um tempo indeterminado até serem libera- 
dos sem explicação; ou tinham sua situação legalizada ao serem levados para uma das prisões da ditadura, sob disposição do Poder Executivo Nacional. As prisões eram partes deste mesmo plano repressivo, articuladas com os espaços clandestinos através da circulação de presos e sequestrados; e do uso de práticas contra os presos que foram comuns nos centros clandestinos como a sua desestruturação física e psicológica, a tortura, o assassinato e o desaparecimento (Memoria Abierta, 2010; Águila, 2013; Garaño, 2020).

Com os desaparecimentos, os militares adotaram uma prática clandestina e anônima. Uma "repressão mais encoberta" dificultava a produção de denúncias sobre a sua dimensão, seus responsáveis e seu objetivo final - o extermínio dos desaparecidos. Além disso, o entendimento por parte da sociedade de que era "apenas mais um golpe"; as diversas respostas sociais às demonstrações de violência na esfera pública; a inexistência de corpos que tornava os desaparecimentos "mortes inconclusas"; as informações fragmentadas e as diferentes versões que circulavam em canais restritos; as negativas oficiais ao reconhecimento dos sequestros e aos pedidos de informação sobre os desaparecidos; e as dificuldades de se atribuir as devidas responsabilidades pela violência tornaram-se obstáculos para a produção de saberes sobre a repressão.

Por outro lado, Gabriela Águila aponta para a existência de facetas públicas do terror estatal. Alguns sequestros ocorreram à luz do dia, diante de testemunhas; ou foram o resultado de grandes operativos em "zonas liberadas", com a presença de agentes uniformizados armados, que cercavam ruas e ameaçavam os vizinhos. Os desaparecimentos deixavam marcas em espaços de sociabilidade, de estudo e de trabalho dos desaparecidos. O "por algo será" costuma ser apontado em testemunhos posteriores como um rumor que circulava socialmente para justificar os sequestros devido às possíveis atividades e vínculos de suas vítimas. Os meios de comunicação informavam sobre o aparecimento de "corpos de subversivos". Alguns centros clandestinos eram parte da trama urbana de grandes cidades (Águila, 2010). Para Emilio Crenzel, o reconhecimento de tais expressões públicas não nos permitem inferir que havia um conhecimento difundido sobre como operava a repressão. Essa confusão pode ser percebida inclusive entre os atores envolvidos na denúncia humanitária que, ao longo da ditadura e mesmo após ela, demonstraram um conhecimento heterogêneo sobre a trama, a dimensão, o objetivo e as responsabilidades por trás dos desaparecimentos, como demonstram seus debates e conflitos sobre a natureza dos desaparecimentos e sobre quais estratégias deveriam adotar para denunciá-la (Crenzel, 2021). 
Frente a tais obstáculos, os organismos de direitos humanos tiveram como um de seus eixos de ação a difusão e denúncia pública das violações para conseguir solidariedade e apoio na resistência à ditadura e salvar vidas. Uma das estratégias então adotadas foi a recepção de testemunho para acumular informações sobre os casos individuais e poder interceder na recuperação dos desaparecidos. Nesse processo, foi essencial a colaboração entre familiares de vítimas e organismos que se adaptaram às novas urgências ou que surgiram durante a ditadura. É necessário ter em vista que nem todas as famílias reagiram da mesma forma. Antes mesmo do golpe, circulavam discursos públicos de condenação e repúdio às atividades da guerrilha, direcionados sobretudo aos setores identificados com ela - os operários e a juventude (Franco, 2012). Estes discursos se incrementaram durante a ditadura, somando-se outros que responsabilizavam os pais pela "subversão" e pelo destino dos filhos, produzindo assim o estigma de ter um familiar "subversivo"/desaparecido, além de medo e silêncio em muitas famílias atingidas. Outras romperam o isolamento social e passaram a buscar formas de montar o "quebra-cabeça" dos desaparecimentos, buscando contatos pessoais nas Forças Armadas, na religião e na política e instituições (delegacias, quartéis, hospitais, necrotérios, manicômios, tribunais, Ministério do Interior, consulados) que no passado foram referências na intermediação com o Estado (Da Silva Catela, 2001; Jelin, 2017).

Sobretudo entre 1976 e 1979, a Justiça, que havia se tornado anteriormente um campo de ação das comissões de solidariedade e dos organismos, oferecia possibilidades limitadas de intervenção, pois a engrenagem institucional da ditadura limitou a possibilidade de se utilizar o sistema jurídico para a proteção da integridade das vítimas da repressão. Mesmo com tais limitações e as respostas negativas à maioria dos habeas corpus, eles ainda foram uma das estratégias mais utilizadas. $\mathrm{O}$ apelo a este recurso jurídico se relacionou a uma crença de que os desaparecidos poderiam estar presos em algum lugar sem causas judiciais iniciadas ou em "centros de recuperação", uma versão recorrente nos primeiros anos da ditadura. Portanto, a interpelação jurídica poderia garantir a sua integridade física. Porém, muitos familiares tiveram dificuldade em encontrar advogados que assinassem os habeas corpus, pois, antes mesmo do golpe, profissionais que contribuíam com organismos de direitos humanos ou de solidariedade com os presos políticos, que tinham algum tipo de militância política, ou que haviam apresentado habeas corpus a favor de pessoas desaparecidas, tornaram-se vítimas de sequestros e desaparecimentos ou se exilaram (Memoria Abierta, 2010). 
Os organismos de direitos humanos se afirmaram então como espaços de aconselhamento jurídico e de recepção de denúncias. Inicialmente utilizadas para a produção de habeas corpus, ao longo da ditadura, o uso destas denúncias se difundiu em outros documentos, de acordo com as lógicas e as estratégias de cada organismo. Nos primeiros anos, o contato entre os familiares ou com companheiros de militância dos desaparecidos foi importante para que circulasse entre eles informações sobre a existência desses espaços, principalmente entre aqueles que não tinham atuação política prévia. Esta circulação permitiu aos familiares compreenderem que o que lhes estava acontecendo era um problema de "direitos humanos" e de sua violação (Da Silva Catela, 2001).

Graciela Fernández Meijide, por exemplo, soube da existência da APDH através da mãe de María e de Leonora Zimmerman, sequestradas no mesmo operativo que seu filho Pablo, em 23 de outubro de 1976 (Meijide, 2009). Durante a ditadura, a ADPH centralizou o registro de denúncias, recebendo mais de 5.000 testemunhos. Os contatos de membros da APDH com familiares das primeiras pessoas desaparecidos foi uma das razões que motivou a fundação do organismo, em dezembro de 1975. Com o aumento no número de casos, o trabalho da APDH orientou-se aos desaparecimentos, por meio do aconselhamento jurídico a familiares para a produção de habeas corpus e da produção e recepção de testemunhos. Em novembro de 1976, a APDH colaborou ativamente com os observadores da Anistia Internacional (AI) durante sua missão na Argentina. Essa colaboração permitiu ao organismo internacional reunir centenas de testemunhos de familiares de desaparecidos, de refugiados latino-americanos no país e de presos políticos em distintas prisões (Gutman, 2015).

Segundo Fernandez Meijide, para que uma denúncia fosse validada, solicitava-se que um responsável por ela apresentasse seu documento de identificação e a constância escrita de alguma apresentação feita à polícia ou à justiça. Estes requisitos eram uma forma da $\mathrm{APDH}$ evitar que os serviços de inteligência saturassem o organismo com denúncias falsas para desprestigiar e anular sua tarefa (Meijide, 2009). Os testemunhos eram então organizados em fichas que, por padronizar as informações, possibilitaram as primeiras recopilações de dados que sistematizaram as informações então dispersas em denúncias individuais. Em abril de 1977, pouco mais de um ano depois do golpe, a APDH elaborou um habeas corpus coletivo para a Corte Suprema de Justiça com 425 casos. Conhecida publicamente como o caso "Peréz de Smith", esta é considerada a primeira lista de desaparecidos produzida na Argentina e trazia o relato geral de cada sequestro (Balardini, 2015; Díaz, 2003; Veiga, 1985). 
Outro organismo que logo recebeu testemunhos sobre os desaparecimentos foi o MEDH. Sob influência da Teologia da Libertação e de organismos de direitos humanos de origem religiosa que atuavam em outros países do Cone Sul, o MEDH foi fundado em fevereiro de 1976, com o objetivo de criar um espaço que colaborasse no acompanhamento das vítimas da repressão, desde um ponto de vista ecumênico. Um dos referentes deste organismo, o bispo de Quilmes Jorge Novak, aponta que a sua incorporação se relacionou à escuta cada vez mais frequente de relatos de familiares de desaparecidos que buscavam na sua congregação apoio e consolo religioso (Ginzberg, 2003). Ao longo da última ditadura, o MEDH atendeu principalmente familiares com recursos econômicos limitados que chegavam ao organismo através de indicações de religiosos locais. Para estas famílias, o MEDH desenvolveu ações de apoio jurídico e econômico. Além disso, as denúncias realizadas por elas no $\mathrm{MEDH}$ formaram um "arquivo social", que registrou a história de vida de cada família (Balardini, 2015).

\section{OS ORGANISMOS DE FAMILIARES DE DESAPARECIDOS E SUAS INICIATIVAS PARA TORNAR PÚBICOS OS TESTEMUNHOS SOBRE OS DESAPARECIMENTOS}

A produção de informação sobre os desaparecidos não foi uma das tarefas centrais da LADH. A LADH seguiu sua tradição histórica de prover assistência jurídica e material aos presos políticos e seus familiares. Este trabalho lhe permitiu apresentar na Europa, em fevereiro de 1976, uma lista com nomes de 4.000 presos à disposição do $\mathrm{PEN}$, com seus nomes e a prisão e o pavilhão em que estavam alojados (Balardini, 2015). Em relação aos desaparecidos, a LADH teve um papel importantes nas maneiras como se organizaram as primeiras ações públicas e coletivas dos familiares. Desde fevereiro de 1976, este organismo foi um ponto de encontro de familiares que, depois de recorrer dependências oficiais e igrejas, pareciam esgotar seus recursos de busca (Casola, 2010; Gorini, 2006).

Seguindo uma política aplicada ao longo de sua história, em setembro de 1976, a LADH impulsionou a organização da primeira "Comissão de Familiares" em Buenos Aires, que em 1977, adotou o nome de Familiares de Desaparecidos y Detenidos por Razones Políticas. O encontro de familiares na sede da LADH foi um passo importante para a seu entendimento de que os desaparecimentos não eram casos isolados, mas parte de um plano sistemático com um modus operandi específico. Do grupo inicial, alguns familiares eram militantes peronistas, comunistas e trotskistas. Além disso, havia familiares de presos que participaram das comissões de solidariedade formadas antes do golpe. A presença destes familiares 
com experiências diversas de militância e o contato com militantes experientes da LADH foram fundamentais para a formação do primeiro organismo de familiares de vítimas da violência estatal (Casola, 2010).

$\mathrm{O}$ fato de ter um espaço próprio permitiu a Familiares desenvolver tarefas internas similares as dos outros organismos como, por exemplo, a produção de testemunhos. Em seu testemunho para o Arquivo Oral do Memoria Abierta, Graciela Lois recorda-se que sua aproximação de Familiares ocorreu em dezembro de 1976, pouco depois do desaparecimento de seu marido, Ricardo Lois, em 07 de novembro de 1976, dedicando-se à toma de testemunhos. Esta era uma tarefa específica dos "mais jovens" (irmãos, irmãs e conjugues de desaparecidos), pois acreditava-se que era mais seguro evitar sua exposição em tarefas externas. A toma de testemunho consistia em perguntas que permitissem identificar a pessoa desaparecida e recopilar informações sobre o seu desaparecimento. Produzia-se então um relato completo e fichas nas quais eram ingressados dados básicos que facilitassem o seu uso. Apesar de Familiares adotar o "por razões políticas" em seu nome, denunciando as militâncias como causas das detenções e desaparecimentos, Graciela aponta que não se perguntava sobre isso (Memoria Abierta, 2015).

Em relação às tarefas externas, houve um aprendizado com os militantes da LADH sobre a importância de tornar públicas as denúncias. Para tanto, Familiares estimulou o envio de cartas a autoridades nas quais se expunham os testemunhos individuais (Casola, 2010). Além disso, ao longo de 1977, organizou a publicação de quatro matérias pagas em jornais argentinos, com as assinaturas de familiares que pediam pelos desaparecidos e pela liberdade dos presos políticos. Na produção da primeira delas, por motivo do primeiro aniversário do golpe de 24 de março, participaram a LADH e a APDH para depurar uma lista de desaparecidos a partir das denúncias em poder dos três organismos (Balardini, 2015). Em 14 de outubro, Familiares organizou uma manifestação pública durante a entrega de um petitório à Comisión de Asesoramiento Legislativo, organismo responsável pela sanção de decretos e leis. Esta manifestação foi reprimida e, em resposta, Familiares organizou uma conferência de imprensa onde correspondentes estrangeiros reuniram informações sobre a mobilização anti-ditatorial na Argentina (Familiares de Desaparecidos y Detenidos por Razones Políticas, 1988).

Os correspondentes estrangeiros desempenharam também um papel importante na circulação no exterior dos testemunhos das Madres de Plaza de Mayo. Formado em 1977, este organismo reuniu mães de desaparecidos que em sua maioria se conheceram durante suas buscas individuais e começaram a juntar-se para trocar informações. Algumas delas participavam regularmente das reuniões pro- 
movidas na sede da LADH, mas não se incorporaram a Familiares. Algumas mães de desaparecidos começaram então a se reunir como um grupo paralelo a Familiares, mas durante a ditadura era comum que algumas mulheres participassem dos dois espaços (Casola, 2010; Gorini, 2006).

A ação mais notória das Madres foram as rondas na Praça de Maio iniciadas em 30 de abril de 1977. Nelas, compartilhar testemunhos foi uma forma de gerar o reconhecimento mútuo entre mulheres que lidavam com situações parecidas, além de um conhecimento da extensão da repressão. Para Nair Amuedo, a Praça era um lugar onde ela podia falar com a madre que caminhasse ao seu lado sobre as circunstâncias do desaparecimento de sua filha, Patricia Rosana Madalena de Romero, desaparecida em 28 de agosto de 1976. Para Ilda Micucci, mãe de Daniel Bernardo e Viviana Micucci, desaparecidos em 11 de novembro de 1976, a possibilidade de escutar os casos contados por outras madres lhe permitiu montar um panorama do que estava acontecendo (Madres de Plaza de Mayo Línea Fundadora, 2014).

Além das rondas, um dos princípios fundacionais adotados por Madres em 1977 foi a denúncia dos desaparecimentos. Em relação às denúncias locais, as primeiras iniciativas foram a participação na produção das matérias pagas em colaboração com Familiares; realização de audiências com autoridades militares, diplomáticas e da Igreja Católica; e a presença em atos públicos onde estivessem funcionários argentinos ou estrangeiros, nos quais começaram a se distinguir dos outros familiares pelo uso de um pano branco na cabeça, o pañuelo. A presença das madres nestes eventos chamou a atenção dos meios de comunicação locais e internacionais que publicaram as primeiras notícias sobre as "loucas" da Praça de Maio e suas vigílias semanais, que geravam debates com outros organismos sobre a sua serventia (Casola, 2010).

Em julho de 1978, durante a cobertura da Copa do Mundo realizada na Argentina, as madres ganharam destaque na cobertura da imprensa estrangeira, apesar dos esforços da ditadura de tentar mitigar as denúncias que já circulavam no exterior sobre as violações aos direitos humanos, principalmente durante as campanhas na Europa de boicote ao evento (Jensen, 2010). Alguns jornalistas estrangeiros dedicaram-se então à cobertura do campeonato e a coletar testemunhos de mulheres que buscavam por seus filhos desaparecidos. Os contatos entre as Madres e os jornalistas estrangeiros resultou em 1980, na publicação em Paris do livro Les folles de la place de mai ("As loucas da Praça de Maio"), escrito pelo correspondente da France-Presse, Jean-Pierre Bousquet. Bousquet residiu em 
Buenos Aires entre 1975 e 1980, que traz em seu conteúdo alguns testemunhos, sobretudo de mães de desaparecidos (Basile, 1998).

A partir de 1978, às estratégias de denúncia local, se intensificou a denúncia de Madres no exterior. Entre 1978 e 1979, elas realizaram suas primeiras viagens ao exterior para denunciar os casos de desaparecimento em espaços como a Organização dos Estados Americanos (OEA) e a Organização das Nações Unidas (ONU) (Madres de Plaza de Mayo Línea Fundadora, 2014). A sua circulação no exterior se legitimava no fato delas personificarem alguns valores que então se afirmavam nas redes transacionais de direitos humanos e que eram preconizados pela política de direitos humanos de países como os Estados Unidos: eram familiares de vítimas, sem intenções políticas além da resolução de um drama moral e privado (Gorini, 2006). Além disso, uma prática comum das madres nesse momento, foi o envio de cartas ao exterior para denunciar os desaparecimentos e sensibilizar a opinião pública internacional sobre a luta anti-ditatorial (Catoggio, 2018).

O envio de testemunhos para o exterior foi uma estratégia assumida também por Abuelas de Plaza de Mayo. Abuelas surgiu no final de 1977, a partir de um grupo de doze mulheres no interior de Madres que, sem se separar inicialmente, iniciou uma busca em paralelo por seus netos desaparecidos, sequestrados junto com seus pais ou nascidos durante o sequestro de suas mães. Um dos aspectos distintivos da repressão implementada pela última ditadura argentina foi a apropriação dos filhos e filhas dos desaparecidos. Considerados "botins de guerra", estas crianças tiveram suas identidades falsificadas após serem adotadas através de procedimentos de maior ou menor ilegalidade, rompendo assim todo o vínculo com suas famílias biológicas e ocultando-lhes sua origem e sua história (Laino Sanchis, 2020b).

Em maio de 1977, treze avós assinaram um habeas corpus coletivo em forma de carta, no qual denunciavam os primeiros casos de apropriação e solicitavam a cessão dos processos de adoção (Dandan, 2006). As primeiras reuniões para articular estratégias de denúncia e de busca de seus netos desaparecidos ocorreu em outubro. Nesse momento, as madres-abuelas produziram um documento com os casos das crianças e das mulheres grávidas desaparecidas, entregue ao Secretário dos Estado Unidos, Cyrus Vance, durante sua visita à Argentina em novembro de 1977. Este documento foi produzido em paralelo a outro pelas Madres sobre os casos de seus filhos desaparecidos (Abuelas de Plaza de Mayo, 2007).

Paulatinamente, Abuelas foram assumindo a sua independência em relação a Madres, devido, entre outros motivos, ao entendimento da especificidade 
de sua ação na investigação sobre o paradeiro dos netos desaparecidos (Laino Sanchis, 2020a). Esta investigação pressuponha, por um lado, averiguar denúncias de adoções suspeitas; por outro, sistematizas as informações aportadas através de testemunhos sobre cada caso de mulheres grávidas e de crianças desaparecidas. Nesse processo, se somaram aos testemunhos dos familiares dos desaparecidos, os relatos de sobreviventes que saíam com vida dos centros clandestinos de detenção e que traziam informações sobre as mulheres grávidas vistas por eles com vida. Estela de Carloto, por exemplo, recorda-se que, em abril de 1978, uma sobrevivente que esteve sequestrada com sua filha, Laura, no centro clandestino de detenção La Cacha, em La Plata, contou a seu marido que Laura estava bem, e que sua gravidez de seis meses seguia bem, confirmando para sua família que ela estava grávida. No início dos anos de 1980, no Brasil, Estela conheceu Alcira Rios, outra sobrevivente exilada que lhe confirmou que Laura havia tido um filho (Di Marco, s.d.).

Os dados reunidos por cada abuela, eram então organizados em fichas que se dividam em dois tipos. O primeiro tipo compilava informações sobre bebês sequestrados juntos com seus pais, incluindo suas informações pessoais, o nome de seus pais e informações sobre onde e quando ocorreu o seu sequestro. Em seguida, agregava-se o nome de quem havia feito a denúncia, seu parentesco com a criança, os trâmites realizados e um testemunho do sequestro. Já o segundo tipo de fichas diferenciava-se por se concentrar nos dados sobre os pais, trazendo apenas uma data provável de nascimento e o provável nome da criança. A partir dessas fichas, Abuelas produziram dossiês sobre cada caso que incluíam ainda fotografias, documentos pessoais dos pais desaparecidos e um testemunho de cada avó sobre sua história familiar, de modo a garantir a credibilidade da denúncia feita. A preocupação com a credibilidade se relacionava com o fato da apropriação de bebês por motivos políticos ser até então um crime inédito. Estes dossiês foram enviados para organizações no exterior e entregues em juizados de menores em Buenos Aires (Abuelas de Plaza de Mayo, 2007; Balardini, 2015).

\section{A PRODUÇÃO DE INFORMES SOBRE OS DESAPARECIDOS}

A partir de 1979, a formação do Centro de Estudios Legales y Sociales (CELS) e a vista à Argentina da Comissão Interamericana de Direitos Humanos (CELS), produziram algumas mudanças na produção dos testemunhos sobre os desaparecimentos e nos seus usos. Por meio de distintas iniciativas de sistematização de informação, os testemunhos saíram das fichas ou cartas que denuncia- 
vam casos individuais para a produção de um conhecimento sobre padrões repressivos e sobre os crimes da ditadura, particularmente o desaparecimento, buscando torná-lo um problema jurídico. Dessa forma, para além do trabalho de "caso a caso" ou a elaboração da "lista de desaparecidos", produziram-se documentos que materializaram a dimensão das violações aos direitos humanos até então ocultadas e negadas pela ditadura e que produzissem um entendimento sobre eles. O resultado desse trabalho foi a produção de informes que tinham a noção de detido-desaparecido como fenômeno central do acionar repressivo, além da elaboração de uma tipologia dos desaparecidos a partir de padrões encontrados nos testemunhos. (Balardini, 2015; Basualdo, 2019).

Uma vez confirmada a visita da CIDH no final de 1978, os organismos compreenderam a necessidade de entregar-lhe, para além de uma lista atualizada de desaparecidos, um trabalho mais orientado, que garantisse que pelo menos uma parte dos testemunhos reunidos recebesse o devido tratamento pela Comissão. Os testemunhos saíram, assim, das fichas individuais de denúncias e das listas de desaparecidos para tornar-se parte da produção de um conhecimento sobre padrões repressivos e sobre os crimes da ditadura, particularmente o desaparecimento, convertendo-o em um problema jurídico. Dessa forma, para além do trabalho de "caso a caso" ou a elaboração da "lista de desaparecidos", produziramse denúncias que materializassem a dimensão dos crimes até então ocultados e negados pela ditadura e que produzisse um entendimento sobre eles (Balardini, 2015; Basualdo, 2019).

Uma dessas iniciativas foi realizada por advogados da APDH e do incipiente CELS que, a partir das 5.581 denúncias reunidas por distintos organismos - APDH, LADH, MEDH, Familiares e Madres - selecionou 300 casos. Estes casos foram apresentados à CIDH, por meio de um informe que tinha a noção de desaparecido como fenômeno central do acionar repressivo. Foram então selecionados aqueles que permitissem caracterizar uma situação de violação aos direitos humanos, para além da denúncia de um caso individual. Como resultado, o informe elaborou uma tipologia dos desaparecidos a partir dos padrões encontrados pelos advogados, baseada em categorias que demonstravam quais grupos sociais haviam se tornado alvo da repressão.

Segundo Emilio Crenzel, a classificação dos desaparecidos através de variáveis ocupacionais, democráticas ou religiosas fez parte de um processo de homogeneização do discurso humanitário, após o golpe no Chile. Buscava-se, assim, restituir a humanidade das vítimas negadas pelo Estado, ao associar um nome e dados identitários a cada caso. Por outro lado, afastava os casos denun- 
ciados dos motivos políticos nos quais se baseou a repressão, ao omitir dados sobre as vinculações políticas dos desaparecidos (Crenzel, 2021). Nesse processo, algumas "categorias de desaparecidos" eram mais legítimas e tinham seu uso mais difundido do que outras, principalmente aquelas que permitiam denunciar os aspectos mais perversos dos processos repressivos. Dessa forma, no informe produzido pela APDH e pelo CELS em 1979, notamos a utilização de categorias como: jovens menores de 18 anos; soldados que cumpriam com o serviço militar obrigatório; mulheres grávidas e famílias atingidas pela repressão.

O diferencial desse tipo de denúncia para as denúncias que os organismos de direitos humanos até então produziam é que, além dos dados pormenorizados sobre cada caso de desaparecimento denunciado, incluía-se uma interpretação sobre o conjunto de casos. Dessa forma, na Introdução ao informe responde-se aos argumentos da ditadura de que os desaparecimentos eram resultados da "luta antisubversiva", destacando uma suposta inocência das vítimas. Esta inocência se baseava no fato de que, em muitos casos, as vítimas não possuíam ideologia alguma; foram sequestradas por suspeitas "infundadas" ou por procedimentos "incorretos", devido a suas relações de amizade ou familiares; e, aquelas que estavam vinculadas a grupos políticos, estes não tinham a ver com a "subversão", ou seja, com as organizações político-militares, apesar de formar o espectro de oposição à ditadura. Além disso, o documento está dividido em duas partes. Na primeira, são apresentados alguns testemunhos na íntegra, sem qualquer mediação. Na segunda, de título "Análisis", é apresentada cada categoria que permite um entendimento da repressão clandestina durante a ditadura por meio das conclusões tiradas pelos advogados que participaram de sua produção e da alusão a testemunhos que as ratificam. ${ }^{2}$

Em paralelo a este trabalho de categorização dos desaparecidos, houve um esforço de produzir estatísticas que materializassem por escrito um entendimento sobre a repressão e os desaparecimentos que até então circulava verbalmente entre os militantes de direitos humanos. Em seu testemunho para o Arquivo Oral do Memoria Abierta, Graciela Lois aborda a sua participação nos processos de produção destas estatísticas em Familiares:

(...) lo que hicimos fue armar una presentación que incluso hicimos con estadísticas, hicimos la presentación de los años, la cantidad de hombres y mujeres, la edad, y la franja etaria, donde tenían más desapariciones, las profesiones, porque decíamos tantos estudiantes, tantos obreros, todo eso que fue muy artesanal, porque bueno yo, como estudiaba Arquitectura,

${ }^{2}$ Arquivo do CLAMOR, Denúncia No 104. 
y sabía más o menos controlar el tema de las pirámides y de las barritas, los fuimos armando, y eso fue una presentación más completa todavía. (Memoria Abierta, 2015)

O trecho citado aponta ainda para a construção de uma legitimidade da denúncia aportada pelos organismos de direitos humanos à $\mathrm{CIDH}$, que se baseava no uso de um saber profissional (seus conhecimentos como estudante de Arquitetura) em sua produção. Dessa forma, para além do efeito moral da denúncia e do apelo a valores como a os vínculos de parentesco, buscava-se garantir que a informação aportada por ela era confiável, pois sua produção baseava-se em critérios e metodologias próprias de saberes científicos (Balardini, 2015).

As duas mudanças nas práticas dos organismos de direitos humanos a produção de informes sobre os desaparecidos e o apelo a uma legitimidade das suas práticas baseados em saberes reconhecidos - podem ser percebidas nas iniciativas desenvolvidas pelo CELS nos últimos anos da ditadura. O CELS foi formado oficialmente em 14 de março de 1980, por um grupo de cinco homens que tinham seus filhos desaparecidos ou presos e que, até então, participavam da APDH. A sua opção por criar um organismo próprio relacionou-se às discussões em torno das resistências da APDH em utilizar a categoria "desaparecido" em suas denúncias e em realizar denúncias judiciais de casos individuais, além dos habeas corpus coletivos (Jelin, 2017).

A proposta dos fundadores do CELS, era criar um organismo que intervisse na opinião pública nacional e internacional com uma interpretação sobre os desaparecimentos e os seus responsáveis materiais. A partir do conhecimento acumulado ao longo da sua participação na APDH, buscavam formas de demonstrar que os desaparecimentos não eram fatos isolados ou "excessos" da repressão, mas formavam parte do projeto político da ditadura e de um plano sistemático de caráter terrorista, colocado em prática através das estruturas do Estado. Para tanto, defendiam três linhas de ação: a criação de um centro de documentação; a realização de investigações e de estudos que permitissem a publicação e difusão de trabalhos destinados a explicar por meio de critérios científicos a repressão desenhada e executada pelas Forças Armadas; e a produção de causas judiciais individuais que permitissem o acúmulo de provas contra os responsáveis pelos desaparecimentos. Dessa forma, além das estratégias legais, o CELS se dedicou à produção de informes sobre a natureza e a magnitude dos crimes da repressão na Argentina (Tahir, 2011).

A primeira apresentação pública feita a partir das conclusões dos trabalhos de investigação do CELS ocorreu em janeiro de 1981, no "Colóquio de Paris sobre a política de desaparecimento forçado de pessoas", realizado no Senado e 
na Câmara de Deputados da França. Este colóquio foi uma iniciativa de um grupo de advogados argentinos exilados na França, para proporcionar um espaço prestigiado aos organismos de direitos humanos argentinos e apoiar a renovação do Grupo de Trabalho sobre Desaparições Forçadas, criado neste ano na ONU. Mignone apresentou então uma descrição detalhada do sistema repressivo da ditadura produzido por ele e por Augusto Conte sobre a base dos testemunhos reunidos pelo CELS e pela APDH (Mignone, 2006).

$\mathrm{Na}$ Argentina, a orientação jurídica do CELS foi fundamental nos últimos anos da ditadura para dotar de um marco legal os testemunhos sobre os desaparecimentos. Estes testemunhos foram utilizados para armar causas sobre sequestro e privação ilegal com as quais os advogados do CELS interpelavam a Justiça. Nesse processo, além dos testemunhos dos familiares de desaparecidos que até então haviam encontrado diferentes espaços de recepção e de produção entre os organismos de direitos humanos locais, paulatinamente surgiu um novo perfil de testemunha: os sobreviventes dos centros clandestinos de detenção.

As possibilidades dos homens e mulheres que saíram com vida dos espaços clandestinos da repressão durante a ditadura de denunciar o seu próprio desaparecimento, além do que haviam visto e escutado nos centros clandestinos de detenção, eram limitadas. Uma possiblidade que pudemos reconstruir nesse momento foi a sua aproximação com familiares de pessoas vistas por eles com vida, às quais traziam informações sobre onde estiveram sequestrados. No arquivo do Comitê de Defesa dos Direitos Humanos no Cone Sul (CLAMOR), por exemplo, encontramos algumas denúncias enviadas por carta, por familiares nas quais eles registraram o seu contato com os "liberados" que confirmavam a passagem dos seus seres queridos por algum centro clandestino. As informações reunidas pelos familiares com os "liberados" confirmavam que os sequestros haviam ocorrido, apesar das respostas oficiais negativas para os habeas corpus apresentados junto aos tribunais e ao Ministério do Interior; apontavam a possível localização do familiar desaparecido e qual a força de segurança responsável pela sua detenção; e deixavam em aberto a possibilidade de ele ainda estar vivo, o que legitimava a sua busca (Tolentino, 2020).

Já nos arquivos dos organismos de direitos humanos na Argentina, até o surgimento do CELS, não encontramos registros de iniciativas desenvolvidas pelos organismos voltadas para este perfil de vítima. Este cenário foi diferente no exterior, pois alguns sobreviventes encontraram no exílio espaços para a elaboração e a apresentação pública de suas denúncias, o que fez com que paulatinamente 
suas vozes surgissem em documentos produzidos em distintos países e por distintas organizações de direitos humanos (González Tizón, 2021; Tello, 2015).

Em 1980, o CELS realizou um trabalho coletivo de investigação e de denúncia judicial sobre o funcionamento do centro clandestino de detenção $E l$ Vesubio, que contou com a participação de sobreviventes, em sua maioria membros de uma organização maoísta, Vanguardia Comunista (VC), e de familiares de desaparecidos deste partido. Neste mesmo ano, em seu "Informe sobre la situación de los derechos humanos en la Argentina", o CELS ressaltou a importância do testemunho dos sobreviventes, por suas possibilidades de reconstruir os procedimentos utilizados durante o operativo de sequestro e nas etapas de interrogatório e de "cativeiro" clandestino. Graças a seus relatos, apontou o Informe, tinha sido possível para o CELS estabelecer a localização de centros clandestinos de detenção e, inclusive, apontar em alguns casos qual era a força de segurança responsável pelo seu funcionamento (González Tizón, 2018).

Dois anos depois, o CELS voltaria a utilizar os testemunhos do grupo de sobreviventes de $E l$ Vesubio como elemento central para a produção do informe "Un caso judicial revelador". Este informe foi parte de uma série de cinco investigações repartidas pelo CELS gratuitamente durante a realização da "Marcha por la Vida", em outubro de 1982. No prólogo que acompanhava cada um deles, o organismo apontava que esta série de informes tinha como objetivo difundir na opinião pública alguns aspectos do sistema repressivo aplicado pelas Forças Armadas desde 24 de março de 1976. Cada informe trazia em si a análise de um aspecto da repressão ilegal e clandestina sistematizada pela última ditadura, apresentado por meio da abordagem de alguma metodologia repressiva específica ou de algum perfil de vítima. Em conjunto, eles demonstravam a existência de um sistema normativo paralelo de caráter secreto, aplicado pelas hierarquias militares. Para tanto, os testemunhos eram peças que permitiam formar um quadro "preciso" da doutrina e dos métodos utilizados pelos militares contra vastos setores da população. Além disso, o CELS aponta que a produção desses informes se baseou em um "dever de consciência" e no cumprimento de uma "exigência patriótica" de garantir uma "convivência democrática", que só seriam alcançadas caso conduzidas pelos ideais da verdade e da justiça (CELS, 1982).

As iniciativas desenvolvidas pelo CELS apontam, assim, para um entendimento por parte deste organismo dos testemunhos de familiares de desaparecidos e de sobreviventes dos centros clandestinos de detenção como elementos de prova dos crimes cometidos pela repressão durante a última ditadura e da sua importância na formulação de um horizonte de justiça punitiva para os responsá- 
veis por tais crimes. Ao utilizá-los para formular denúncias judiciais e produzir informes distribuídos massivamente, o CELS se posicionava em um cenário institucional no qual, desde 1979, os militares davam demonstrações de que pretendiam terminar a etapa da "guerra anti-subversiva", decretando o encerramento do "problema dos desaparecidos", por meio da aprovação de decretos e dos chamados a alguns setores sociais e políticos para um "diálogo político" sobre a transição para a democracia. Dessa forma, difundir testemunhos sobre os desaparecimentos pode ser entendido como uma estratégia de intervenção nesses debates, contribuindo, assim, para a produção e divulgação de um saber sobre a repressão clandestina, que pudesse ir de encontro às tentativas dos militares de garantir que as violações aos direitos humanos ficassem impunes, nos últimos anos da ditadura (Franco, 2018; Jensen, 2017).

\section{CONSIDERAÇÕES FINAIS}

Com o fim da ditadura, em dezembro de 1983, um dos embates políticos e simbólicos que se colocaram no espaço público foi como apresentar os desaparecidos como vítimas de violações e de crimes aberrantes e sistemáticos, frente a discursos ainda em circulação que reivindicavam ou justificavam a repressão, apontando-os como "subversivos' e "responsáveis por provocar a repressão". A partir de distintas estratégias dos organismos de direitos humanos e das iniciativas desenvolvidas pela Comisión Nacional sobre la Desaparición de Personas (CONADEP) no curso de sua investigação, os desaparecidos passaram a ser apresentados como vítimas, destacando-se o dano produzido neles e nas suas famílias. Sua vitimização se reforçava ainda na sua apresentação como "vítimas inocentes", um discurso de denúncia já utilizado nos espaços de denúncia no exterior e que nesse momento serviu para questionar a atribuição de responsabilidades à "subversão", além de demonstrar o caráter criminoso da repressão. Paulatinamente, os desaparecimentos passaram a ser entendidos como parte de uma "violência massiva e sistemática", que provavam a responsabilidade criminosa das Forças Armadas (Feld \& Franco, 2015, pp. 382-390).

Nesse processo, os testemunhos de familiares de desaparecidos e de sobreviventes dos centros clandestinos de detenção tiveram uma importância central para produzir um conhecimento público sobre as práticas que configuraram o desaparecimento forçado de pessoas durante a última ditadura. Em um primeiro momento, nos primeiros meses de 1984, esses testemunhos ganharam espaço na imprensa local. Porém a sua veiculação se deu em reportagens nas quais prevale- 
ceu um tom macabro e sensacionalista que dificultou um entendimento de quem eram os desaparecidos e porque eles se tornaram vítimas da violência estatal (Feld, 2015). Este entendimento se deu após as investigações da CONADEP que, por meio do seu relatório final, produziu uma narrativa que se tornou um símbolo da memória coletiva dos desaparecimentos na Argentina (Crenzel, 2021). Para a construção do seu relato, as principais fontes utilizadas pela Comissão foram os testemunhos produzidos no marco de sua investigação e aqueles que foram produzidos durante o período ditatorial e que se encontravam dispersos no país e no exterior. De acordo com Emilio Crenzel, a CONADEP teria recebido 5.580 denúncias que a APDH reuniu durante a ditadura, cuja legitimidade e veracidade foi ratificada ao ser utilizados por uma comissão investigativa criada pelo Estado (Crenzel, 2021).

Podemos afirmar, portanto, que a prática de produzir testemunhos sobre os desaparecidos na Argentina não se iniciou com o final da última ditadura. Apesar da sua emergência pública ter se dado durante as investigações da CONADEP, em 1984, e principalmente durante o julgamento de três juntas de comandantes que governaram a Argentina durante a última ditadura, o chamado Juicio a las Juntas, em 1985, desde o início da ditadura distintos organismos de direitos humanos se dedicaram à tarefa de compilar e reunir relatos sobre os sequestros e desaparecimentos. Nesse processo, a bibliografia sobre a história da luta pelos direitos humanos na argentina tende a afirmar um protagonismo de organizações que atuavam no exterior. Em relação aos organismos locais de direitos humanos, é geralmente analisada as suas possibilidades de se inserir em redes transnacionais e de seus militantes circularem por distintos países para realizar suas denúncias. Entretanto, como quisemos demonstrar neste artigo, algumas iniciativas de produção de testemunhos e sua utilização para a produção de documentos jurídicos e de denúncia também ocorreram na Argentina, apesar das possibilidades limitadas de atuação dos organismos de direitos humanos.

A utilização do testemunho como estratégia de denúncia da violência estatal por essas organizações baseou-se em experiências prévias de grupos que atuaram a partir de meados dos anos 1960, na defesa dos presos políticos; nos contatos com as redes transnacionais de direitos humanos e de distintos "circuitos testemunhais" (González Tizón, 2021); mas também pela criação de novas formas de se utilizar as narrativas de familiares de vítimas e de sobreviventes dos centros clandestinos de detenção, em diálogo com as singularidades do repertório de ação de cada organismo. O valor dessa tarefa foi reconhecido quando esses testemunhos foram utilizados pela CONADEP para a construção de um saber 
público sobre a repressão clandestina. A partir de então, o testemunho se afirmou na Argentina como uma das principais provas para a condenação dos responsáveis materiais pelos desaparecimentos, além de um importante veículo de memória, que circulou em distintos espaços, formatos e materialidades, em diálogo com as possibilidades e urgências dos contextos em que foram produzidos.

\section{BIBLIOGRAFIA}

Abuelas de Plaza de Mayo. (2007). La historia de Abuelas: 30 años de búsqueda, 1977-2007.

Águila, G. (2010). Testemunhas e vizinhos: A ditadura na Grande Rosário (Argentina). In S. Quadrat \& D. Rollemberg (eds.), A construção social dos regimes autoritários: Legitimidade, consenso e consentimento no século XX (vol. II, pp. 597-613). Civilização Brasileira.

Águila, G. (2013). La represión en la historia reciente argentina: Fases, dispositivos y dinámicas regionales. In G. Águila \& L. Alonso (eds.), Procesos represivos y actitudes sociales: Entre la España franquista y las dictaduras del Cono Sur. Prometeo.

Alonso, L. (2011). Luchas en plazas vacías de sueños: Movimiento de derechos humanos, orden loca y acción antisistémica en Santa Fe. Prohistoria.

Bacci, C., \& Oberti, A. (2014). Sobre el testimonio: Una introducción. Clepsidra. Revista Interdisciplinaria de Estudios Sobre Memoria, (1), 5-13.

Balardini, L. (2015). Estrategias de producción de información de las organizaciones de derechos humanos en Argentina: Los usos de la sistematización y la estadística en la búsqueda de verdad y justicia [Tese de mestrado, Universidad de Buenos Aires].

Basile, T. (1998). Aproximaciones al "testimonio sobre la desaparición de personas" durante la dictadura y la democracia argentinas. Cuadernos Angers, 2(2), 45-64.

Basile, T., \& Chiani, M. (2020). Introducción. Avatares del testimonio en el Cono Sur. In T. Basile \& M. Chiani (eds.), Voces de la violencia: Avatares del testimonio en el Cono Sur (pp. 8-31). EDULP.

Basualdo, G. (2019). Movilización internacional en dictadura: La visita de la CIDH y la creación del CELS. Teseo.

Blanes, J. P., \& Sáez, G. P. (2015). Avatares del testimonio en América Latina: Tensiones, contradicciones, relecturas... Kamchatka, (6), 1-8.

Bonano, M. (2005). La escritura testimonial y las memorias de Trelew en La patria fusilada de Francisco Urondo y La pasión según Trelew de Tomás Eloy Martínez. Telar, 2(13), 7592.

Bruschtein, L. (2002). Historia de los organismos de derechos humanos: 25 años de resistencia: Servicio de Paz y Justicia (SERPAJ). https://www.comisionporlamemoria.org/archivos/educacion/organismos/dossier2.pdf

Casola, N. (2010). Cuando lo 'nuevo' es tan 'viejo' como 'nuevo' lo ‘viejo': El movimiento de derechos humanos durante la última dictadura militar en Argentina. El papel del Partido Comunista de Argentina y la Liga Argentina por los Derechos del Hombre (1976-1983). Historia Oral, 13(2), 137-155. https://doi.org/10.51880/ho.v13i2.143 
Catoggio, M. S. (2016). Integración latinoamericana: Contra la coordinación represiva y por una policía regional de los derechos humanos. El caso CLAMOR. In P. Funes (ed.), Revolución, dictadura y democracia: Lógicas militantes y militares en la historia argentina en el contexto latinoamericano (pp. 31-57). Imago Mundi. https://doi.org/10.2307/j.ctvfjd125.8

Catoggio, M. S. (2018). Recorrer y tejer las redes del exilio: El caso de una madre de Plaza de Mayo. In S. Lastra (ed.), Exilios: Un campo de estudios en expansión (pp. 237-250). CLACSO.

CELS (Centro de Estudios Legales y Sociales). (1982). Un caso judicial revelador. https://www.cels.org.ar/web/wp-content/uploads/2016/10/Un-caso-judicial-revelador.pdf

Chama, M. (2016). Compromiso político y labor profesional: Estudios sobre psicólogos y abogados en los primeros setenta. Universidad Nacional de La Plata.

Crenzel, E. (2015). Hacia una historia de la memoria de la violencia y los desaparecidos en Argentina. In E. Crenzel \& E. A. Montaño (eds.), Las luchas por la memoria en América Latina: Historia reciente y violencia política (pp. 31-62). Bonilla Artigas; UNAM, Instituto de Investigaciones Sociales.

Crenzel, E. (2021). A memoria dos desaparecimentos na Argentina: A história política do Nunca Más. Letra e Voz.

Da Silva Catela, L. (2001). Situação limite e memória: Reconstrução do mundo dos familiares de desaparecidos da Argentina. Hucitec.

Dandan, A. (2006, 9 de abril). El otro archivo de la memoria. Página/12. https://www.pagina12.com.ar/diario/elpais/1-65380-2006-04-09.html

D’Antonio, D. (2017). Vigilancia, control social y agencia política del activismo por los derechos humanos ante la llegada de la Comisión Interamericana de Derechos Humanos (Argentina, 1979). Izquierdas, (32), 184-202. https://doi.org/10.4067/S071850492017000100184

Di Marco, G. (s.d.). Hablan las Madres y Abuelas de la Plaza de Mayo: Testimonio de Estela Carlotto, presidenta Abuelas Plaza de Mayo. http://www.unsam.edu.ar/escuelas/humanidades/centros/cedehu/material/(35)\%20entrevista\%20Carlotto.pdf

Díaz, D. (2003). Historia de los organismos de derechos humanos: 25 años de resistencia: Asamblea permanente por los derechos humanos. https://www.comisionporlamemoria.org/archivos/educacion/organismos/dossier6.pdf

Eidelman, A. (2018). La actividad paraestatal en la Argentina a principios de los años setenta. In D. D’Antonio (ed.), Violencia, espionaje y represión estatal: Seis estudios de caso sobre el pasado reciente argentino. Imago Mundi.

Familiares de Desaparecidos y Detenidos por Razones Políticas. (1988). Testimonio de nuestra lucha.

Feld, C. (2015). La prensa de la transición ante el problema de los desaparecidos: El discurso del 'show del horror'. In C. Feld \& M. Franco, (eds.), Democracia, hora cero: Actores, politicas y debates en los inicios de la postdictadura (pp. 269-316). Fondo de Cultura Económica. 
Feld, C., \& Franco, M. (2015). Democracia y derechos humanos en 1984, ¿hora cero? In C. Feld \& M. Franco, (eds.), Democracia, hora cero: Actores, políticas y debates en los inicios de la postdictadura (pp. 359-400). Fondo de Cultura Económica.

Franco, M. (2008). El exilio: Argentinos en Francia durante la dictadura. Siglo XXI.

Franco, M. (2012). Un enemigo para la nación: Orden interno, violencia y "subversión”. Fondo de Cultura Económica.

Franco, M. (2015). Do terrorismo de Estado à violência estatal: Problemas históricos e historiográficos no caso argentino. In R. P. S. Motta (ed.), Ditaduras militares: Brasil, Argentina, Chile e Uruguai. Editora UFMG.

Franco, M. (2018). El final del silencio: Dictadura, sociedad y derechos humanos en la transición: Argentina, 1979-1983. Fondo de Cultura Económica.

Franco, M., \& Levín, F. (2007). El pasado cercano en clave historiográfica. In M. Franco \& F. Levín (eds.), Historia reciente: Perspectivas y desafios para un campo en construcción (pp. 31-66). Paidós.

Garaño, S. (2020). Memorias de la prisión política durante el terrorismo de Estado en la Argentina (1974-1983). Universidad Nacional de La Plata, Facultad de Humanidades y Ciencias de la Educación.

García, V. (2016). Testimonio y ficción en la Argentina de la Postdictadura: Los relatos del sobreviviente-testigo. Revista Chilena de Literatura, (93), 73-100. https://doi.org/10.4067/S0718-22952016000200004

González Tizón, R. (2018). Militancia humanitaria y testimonio: Los sobrevivientes de 'El Vesubio' y la denuncia de los crímenes de la última dictadura (1978 2016) [Tese de doutorado, Universidad de General San Martín]. Repositorio Institucional CONICET Digital. https://ri.conicet.gov.ar/handle/11336/78764

González Tizón, R. (2021). 'Los desaparecidos empiezan a hablar’: Una aproximación histórica a la producción testimonial de los sobrevivientes de la dictadura argentina desde el exilio (1976-1983). Páginas, 13(31). https://doi.org/10.35305/rp.v13i31.475

Gorini, U. (2006). La rebelión de las Madres. La Página.

Ginzberg, V. (2003). Historia de los organismos de derechos humanos: 25 años de resistencia: Movimiento ecuménico de derechos humanos. https://www.comisionporlamemoria.org/archivos/educacion/organismos/dossier5.pdf

Gutman, D. (2015). Noviembre de 1976: Un informe en busca de la verdad. Capital Intelectual.

Jelin, E. (2017). La lucha por el pasado: Cómo construimos la memoria social. Siglo XXI.

Jensen, S. (2010). Los exiliados: La lucha por los derechos humanos durante la dictadura. Sudamericana.

Jensen, S. (2017). Los exiliados argentinos y las luchas por la justicia (1976-1981). Estudios, (38), 13-30. https://doi.org/10.31050/re.v0i38.19126

Laino Sanchis, F. A. (2020a). Salir al mundo en tiempos de dictadura: Abuelas de Plaza de Mayo y las redes transnacionales de derechos humanos (1977-1983). Quinto Sol, (24), 1-22. https://doi.org/10.19137/qs.v24i1.2314

Laino Sanchis, F. A. (2020b). La apropiación de niños y niñas en el marco del terrorismo de Estado y las luchas por su restitución en Argentina (1975-actualidad).: Revista Universitaria de 
Historia Militar, (9), 231-259.

Madres de Plaza de Mayo Línea Fundadora. (2014). Las viejas: Madres de Plaza de Mayo Línea Fundadora cuentan una historia. Marea.

Markarian, V. (2006). Idos y recién llegados: La izquierda uruguaya en el exilio y las redes transnacionales de derechos humanos, 1967-1984. Correo del Maestro.

Meijide, G. F. (2009). La historia intima de los derechos humanos en la Argentina. Sudamericana.

Memoria Abierta. (2010). Abogados, derecho y política.

Memoria Abierta. (2015). Testimonio de Graciela Palacio de Lois [Audio].

Mignone, E. F. (2006). Estrategia represiva de la ditadura militar: La doctrina del "paralelismo global". Comihue.

Oberti, A. (2015). Las revolucionarias: Militancia, vida cotidiana y afectividad en los setenta. Edhasa.

Pittaluga, R. (2006). La memoria según Trelew. Sociohistórica, (19-20), 81-111.

Portoriero, E. D. (2017). Excepcionalidad jurídica y contrainsurgencia: Claves para pensar la racionalidad militar en los inicios del terror de Estado en Argentina (1973-1976). Páginas, 9(19), 53-74. https://doi.org/10.35305/rp.v9i19.250

Reboursin, O. (2008). Derribando algunos mitos: acerca de la Liga Argentina por los Derechos del Hombre en el nacimiento y desarrollo del "movimiento de Derechos Humanos". Revista del CCC, 1(3). https://www.centrocultural.coop/revista/3/derribando-algunos-mitosacerca-de-la-liga-argentina-por-los-derechos-del-hombre-en-el

Sarlo, B. (2007). Tempo passado: Cultura da memória e guinada subjetiva. Companhia das Letras.

Scocco, M. (2018). La conformación del movimiento de derechos humanos de Rosario (1970-1985) [Tese de doutorado, Universidad Nacional de Rosario]. Repositorio Institucional CONICET Digital. https://ri.conicet.gov.ar/handle/11336/81052

Scocco, M. (2020). Narrativa y solidaridad de las redes transnacionales de derechos humanos en Argentina. Secuencia, (108). https://doi.org/10.18234/secuencia.v0i108.1807

Sikkink, K. (2006). A Emergência, evolução e efetividade da rede de direitos humanos da América Latina. In E. Jelin \& E. Hershberg (eds.), Construindo a democracia: Direitos humanos, cidadania e sociedade na América Latina (pp. 97-132). Editoria da Universidade de São Paulo.

Slipak, D. (2015). Las revistas montoneras: Cómo la organización construyó su identidad a través de sus publicaciones. Siglo XXI.

Solis, A. C. (2014). De las comisiones a los organismos en Córdoba: Derechos humanos, dictadura y democratización. In R. I. Kotler (ed.), En el país del sí me acuerdo. Los orígenes nacionales e internacionales del movimiento de derechos humanos argentino: De la dictadura a la transición. Imago Mundi.

Tahir, N. (2011). Les associations de victimes de la dictature: politiques de droits de l'homme et devoir de mémoire en Argentine (1976-2007) [Tese de doutorado, Université Paris-Sorbonne].

Tello, M. (2015). Yo acuso: Un análisis antropológico sobre lo jurídico en los primeros testimonios acerca de La Perla. Clepsidra, 2(4), 90-115. 
Tolentino, M. (2020). O Arquivo do CLAMOR e os registros de denúncia sobre a violência estatal na Argentina (1978-1983). Sillogés, 3(1), 158-192.

Vecchioli, V. (2012). Repertorios militantes y expertise jurídica en la defensa de la causa de los Derechos Humanos en la Argentina: el caso de la Liga Argentina por los Derechos del Hombre. Ensemble. Revista electrónica de la Casa Argentina en París, 4(9). https://www.academia.edu/2063611/Repertorios_militantes_y_expertise_jurídica_en_la_defensa_de_la_causa_por_los_Derechos_Humanos_en_la_Argentina_el_caso_de_la_Liga_Argentina_por_los_Derechos_del_Hombre

Veiga, R. (1985). Las organizaciones de derechos humanos. Centro Editor de América Latina.

Wieviorka, A. (1998). L'ère du témoin. Hachette. 